Article

\title{
Expansion, Excess and the Uncanny: Deadly Premonition and Twin Peaks
}

\author{
Julian Novitz \\ Faculty of Health, Arts and Design, Swinburne University of Technology, P.O. Box 218, Hawthorn, \\ Victoria 3122, Australia; jnovitz@swin.edu.au
}

Received: 29 June 2018; Accepted: 3 September 2018; Published: 7 September 2018

\begin{abstract}
The influence of the cult television series Twin Peaks (1990-1991) can be detected in a wide range of videogames, from adventure, to roleplaying to survival horror titles. While many games variously draw upon the narrative, setting and imagery of the series for inspiration, certain elements of the distinctive uncanniness of Twin Peaks are difficult to translate into gameplay, particularly its ability consistently disrupt the expectations and emotional responses of its audience. This paper examines the ways in which the 2010 survival horror title Deadly Premonition replicates the uncanniness of Twin Peaks in both its narrative and gameplay, noting how it expands upon conceptualizations of the gamerly uncanny. It contends that Deadly Premonition's awkward recombination of seemingly inconsistent and excessive gameplay features mirrors the ways in which David Lynch and Mark Frost draw upon and subvert audience expectations for police procedurals and soap operas in the original Twin Peaks in order to generate an uncanny effect. Furthermore, Deadly Premonition uses the theme of possession - a central element of the television series-to offer a diegetic exploration of the uncanny relationship between the player and their onscreen avatar. In these regards, Deadly Premonition provides a rare example of how the subversive uncanniness of Twin Peaks can be addressed through gameplay, rather than solely through the game's narrative or representational elements.
\end{abstract}

Keywords: the uncanny; Deadly Premonition; Twin Peaks; survival horror

\section{Introduction: The Uncanny in Survival Horror Video Games}

The contemporary idea of the uncanny first emerges in a 1906 essay by Ernst Jentsch, in which he characterizes as the psychological state that results from unsettling experiences of uncertainty, particularly in relation to the status of inanimate objects (Jentsch 1995). Jentsch's definition of the uncanny is famously cited and quoted by Sigmund Freud, who rejects Jentsch's conceptualization of the uncanny as intellectual uncertainty, suggesting rather that the inanimate objects that Jentsch identifies as distinctly uncanny- "wax-work figures, ingeniously constructed dolls and automata" (Freud [1919] 1955, p. 226) are such because they combine familiarity and strangeness. In working to transform the familiar into something strange, Freud argues that uncanny objects, narratives and phenomena challenge our sense of reality through the evocation of repressed memories, images and fears. Encounters with doppelgangers, reflections and corpses are also given as examples of potentially uncanny experiences.

The uncanny evokes a dual sense of fascination and repulsion, which made it a common feature of horror and suspense narratives long before the term was first defined. The popular Gothic literature of the nineteenth century often delivers uncanny an uncanny reading experience by encouraging readers to speculate on whether their central mysteries have mundane or supernatural causes, leaving them uncertain as whether the narratives are realistic or fantastical for as long as possible (Botting 2008). Uncanny images, characters and aesthetics have long been a feature of horror cinema, with living characters being frequently contrasted with blank-faced, lurching automata. Dread is powerfully 
evoked on screen by imbuing the familiar and recognizable human form with a fascinating strangeness (Royle 2003). In the Powers of Horror Kristeva (1982) locates the abject within the realm of the uncanny, suggesting that it is represented by border figures that are not quite right and must be cast out in order to survive. Furthermore, both horror literature and cinema frequently evoke a sense of the uncanny through the use of both literal doppelgangers and doubling effects in their narrative structures and imagery (Schneider 2004). These uncanny aesthetics have been translated into video games, particularly those situated within the survival horror sub-category.

Many different varieties of videogames (from action to horror to roleplaying and more) draw upon these traditions in order to deliver uncanny visual effects, frequently confronting the player with human-like yet deformed monsters, and distortions of seemingly familiar environments, like the archetypical abandoned town or haunted house (Holmes 2010). However, uncanniness in a video game can also manifest itself simply through the designers' attempts at representation. The increasingly realistic, yet still strange, representations found in videogames can have an uncanny effect on both players and observers, entering what robotics scientist Masahiro Mori famously defined as "the uncanny valley", where an artificial representation or duplicate becomes increasingly unsettling once it is sophisticated enough to cross a certain level of resemblance (Mori [1970] 2012). The uncanny can also manifest itself through glitches and bugs in the game's design, where distorted images and animations can result in uncanny experiences for the player (Holmes 2010).

Beyond its intentional and unintentional evocations through representational strategies in videogames, uncanniness can emerge as a feature of the gameplay itself when gameplay mechanics and operations that should feel familiar to the player are made to feel strange and unwieldly (Kirkland 2009b). As Holmes (2010) notes, this may occur due to errors or bugs in the game's design, but when this uncanniness is intentionally introduced into the gameplay it is usually used to emphasize a particular movement in the game's narrative, often a change or shift in the physical or mental state of the video game protagonist that the player is controlling. Examples might include the slowed responses to controller inputs that occur when the player enters a hallucinatory dream sequence in Grand Theft Auto 5 (Rockstar North 2013) or the sudden inversion of the player's control scheme that occurs at the climax of Beyond Good and Evil (Ubisoft 2003), when the protagonist is subjected to a psychic assault. In most games, these moments of uncanny gameplay will only occur briefly, so as to avoid frustrating their players. Survival horror games, however, arguably tend to offer more prolonged experiences of uncanny gameplay as their principal aim is to unsettle and destabilize their players, and therefore much of the scholarly discussion of the uncanny in videogames has tended to focus on this category. Gameplay in survival horror titles can easily be understood as uncanny because the games often use controls that are awkward when compared to other titles, so as to create a sense of vulnerability for the player (Perron 2018). Because players are unable to function as effectively as they would in games outside of the survival horror category, actions that would be routine and familiar (e.g., walking or turning) are transformed into tense and nerve-wracking activities. As Thomas Grip puts it: "It (survival horror) is the only genre where it is okay to sacrifice gameplay in order to create emotions and build atmosphere" (quoted in Thomsen 2010). The typical third-person perspective of survival horror games is important in creating an uncanny experience for the player, with their avatar operating as their on-screen double, under their control yet uncomfortably separate from them, extending the frequent doubling effects that Schneider (2004) locates in horror fiction and cinema into gameplay. Tanya Krzywinska argues that the player's third-person control over their onscreen avatar (and the frequent moments when this control is disrupted through the movement to a non-interactive cut scene) can operate as an expression of a recurrent theme in horror fiction and cinema "in which supernatural forces act on, and regularly threaten, the sphere of human agency" (Krzywinska 2002, p. 207). Kirkland (2009b) observes that this relationship between the player and their avatar creates an uncanny space, which "unsettles the boundaries between dead object and living person" and that this is accentuated through the slow and disorienting navigation of threatening, maze-like environments in survival horror titles. Perron (2018) notes that the less immediately 
responsive third person controls and fixed camera angles of classic survival horror work to unsettle the typically close relationship between the player and their avatar in videogames, blurring the subjectivity and objectivity of the player's perspective. Hoeger and Huber (2007) focus on this customarily uneasy relationship between the player and their onscreen avatar in survival horror titles in their discussion of what they define as the "gamerly uncanny", this being the uncanniness that is created through player-directed movement and navigation, and which has its basis in the particular mode of attention that videogames demand.

The gamer is obligated to actively decode and navigate a genre-constructed space of threats and secrets. This navigation is performed by a surrogate-body in that fictive space: the avatar-character whose activities depend on the player's activities. The effort to overcome incoherence takes on a specific kind of urgency, one based on a possibility of death (Hoeger and Huber 2007, p. 153).

While the uncanny hyper-awareness around movement is feature of all videogames, Hoeger and Huber argue that it is particularly important to the evocation of dread in survival horror game, which "thematises and foregrounds the complicated relationship between these virtual bodies and the immersed situation of the player" (2007, p. 153). Conventional video game design would usually attempt to avoid distancing or detaching the player from their onscreen avatar, but survival horror games can evoke tension, dread and anxiety through an avatar that appears incomplete and not wholly human (Tinwell and Grimshaw 2009), or by using narrative and visual strategies that disrupt the player's identification with the onscreen character (Perron 2012).

This common feature of survival horror titles creates a tension between the player's tendency to identify with their avatar and the limitations that survival horror games place on their perception, agency and control. Thus, within games in the survival horror category, the uncanny experience is often generated through the defining features of survival horror gameplay itself rather than just the representational qualities of the setting, visuals and narrative.

However, the "gamerly uncanny" that Hoeger and Huber (2007) define as essential to survival horror can be perceived as limited, or even predictable, in some respects, and this becomes particularly apparent when considering the frequent attempts of various video games (and certain survival horror titles in particular) to reference and homage the cult television series Twin Peaks (1990-1991). The expansive and consistently subversive nature of the uncanny aesthetic of Twin Peaks has been difficult to replicate in gameplay (if not in narrative and representational content), and cannot be easily accommodated by the type of "gamerly uncanny" identified by Huber and Hoeger, which develops out of the strict minimalism of survival horror titles.

\section{Twin Peaks and Video Games}

Frost and Lynch (1990-1991)'s cult television series Twin Peaks is considered a distinctively and unusually uncanny television series (Weinstock 2016), which likely contributes to its continuing influence on a wide variety of media, including videogames, and in particular, survival horror titles. Many of the most memorable scenes and images from Twin Peaks stray into uncanny territory, particularly in the sequences that most closely align with horror or supernatural genres of storytelling. The backwards speech and jerky, distorted movements of the inhabitants of the Red Room serve as an example, as does the leering, malevolent image of Killer BOB, which appears in dreams and reflections. Furthermore, Twin Peaks abounds with both overt and subtle doublings and duplications, which contributes to the uncanniness of its narrative, atmosphere and overall viewing experience.

However, the uncanniness of Twin Peaks also operates at more sophisticated and subversive level in its approach to familiar film and television genres. Jowett (2016) argues that Twin Peaks is unsettling not just because its uncanniness disturbs its viewers in the manner of a classic horror or supernatural narrative but because it frequently disrupts their expectations as to what they are about to see or experience in any given moment. Jowett (2016) contends that Twin Peaks develops its most 
distinctively uncanny effect through the combination of television genres/storytelling traditions that would have been highly familiar to audiences at the time of its first broadcast: the police procedural and the soap opera. The typically self-contained or episodic murder mystery or police procedural is expanded to an unwieldly and perplexing length through its integration into a soap opera, with the usually linear and logical accumulation of detail and evidence being diverted into a tapestry of side narratives, red herrings and dead ends. Similarly, the soap opera-like romances, schemes and conflicts of Twin Peaks' supporting cast take on unusually sinister undertones when they are united by the narrative thread of Laura Palmer's murder. As the series progresses it draws in a range of other genres: supernatural horror, hardboiled noir, melodrama, teen rebel movies and more. The excess of influences and references in Twin Peaks can have a disorienting effect, making it challenging to predict the flow of the narrative or to understand and interpret key events.

The influence of Twin Peaks on video games is arguably felt most strongly in narrative-focused adventure games, such as Life is Strange (Dontnod Entertainment 2015), Virginia (Variable State 2016), Thimbleweed Park (Terrible Toybox 2017), Kathy Rain (Clifftop Games 2016) and other titles, though homages and references to the series can be also be detected in the role-playing series Persona, in particular Persona 4 (Atlus 2008) and the action/horror title Alan Wake (Remedy Entertainment 2010). In so far as these games replicate or draw upon elements of the distinctive uncanniness of Twin Peaks, they do in terms of their representational content-their narratives, characters, settings, and their visual and audio aesthetics - rather than through their gameplay. Videogames typically require their audiences to engage with a limited set of mechanics which are generally determined by the broad category that the game falls into (e.g., role-playing, action, etc.). While the narrative or visual imagery found in the game may work to destabilize the player, the gameplay itself, once mastered, will typically remain familiar.

The influence of Twin Peaks can be detected in survival horror titles as well. Developers of the seminal Silent Hill series have acknowledged its influence on the setting, narrative and visual aesthetic of their games, particularly the highly regarded Silent Hill 2 (Konami 2001) (Perron 2012). However, while survival horror games certainly deliver an uncanny style of gameplay relative to other titles, this "gamerly uncanny" identified by Hoeger and Huber (2007) is incapable of replicating the subversive component of the uncanniness of Twin Peaks-where familiar genres and categories of storytelling are combined in ways that render them strange and subvert audience expectations and responses-due to its own internal consistency and the focused, minimalist aesthetic that classic survival horror encourages through its emphasis on restriction and limitation. As Krzywinska (2015b) notes, survival horror games are defined in large part by the restrictions that they place upon the player relative to other types of games, in terms of movement, in-game resources, field of view and other affordances. Perron (2018) notes that popular discussion of survival horror often tends to focus on its "purity" as a video game category, with the titles that deviate from this minimalist aesthetic (for example Resident Evil 4 [2007] and Silent Hill Homecoming (Konami 2008) which both introduced a greater variety of combat options for players) having their status as "true" survival horror games questioned. While the way in which survival horror foregrounds and complicates the relationship between the player and their avatar can certainly produce an unsettling uncanny effect, it is an effect that will probably be expected, anticipated and appreciated by the player, due to their familiarity with the survival horror category itself and/or their growing familiarity with the systems and mechanics of a specific survival horror title. The spare, stripped-back focus of classic survival horror titles has proven effective in scaring and unsettling players, but it also reveals the limitations of the "gamerly uncanny" that players encounter in these titles, as the minimalism of classic survival horror games makes their features and objectives immediately recognizable. In this sense, the "gamerly uncanny" that is frequently encountered in survival horror is only uncanny due to the contrast that it presents with the gameplay of titles outside of the category, but can become, paradoxically, familiar within it. It works to unsettle the player-but only within strictly defined parameters.

The cult videogame title Deadly Premonition (Access Games 2010) provides a rare example of how the subversive elements of the uncanniness of a show like Twin Peaks can be incorporated into uncanny 
play. Where Hoeger and Huber (2007) principally explore the ways in which the "gamerly uncanny" develops out of the player's relationship with their onscreen avatar, an examination of Deadly Premonition reveals that uncanniness can also be evoked through the destabilizing combination of familiar modes of gameplay. Deadly Premonition replicates the distinctive uncanniness of Twin Peaks by expanding upon some of the gameplay features traditionally associated with survival horror titles. It does so by incorporating elements from other categories of gameplay in ways that render them strange and unfamiliar to experienced players, and also by self-consciously foregrounding the uncanny relationship between the player and their onscreen avatar in its narrative.

\section{Expansion and Excess: Uncanny Play in Deadly Premonition}

Deadly Premonition is a third person survival horror/adventure game in which the player takes the role of an FBI agent, Francis "York" Morgan, who has been sent to investigate the murder of a young woman in the small rural town of Greenvale. Upon arrival, York and the player discover that supernatural forces to be at work as their investigation takes them into a nightmarish otherworld inhabited by hostile ghosts and spirits. Reviews (for example, Sterling 2010; VanOrd 2010; Wales 2010), popular articles (Carmicheal 2013; Green 2017) and scholarly texts (Perron 2018) have all noted the strong influence of Twin Peaks on Deadly Premonition, particularly with regard to its narrative, its small-town setting, the eccentricities of its detective protagonist, and the quirky behavior of Greenvale's residents. While this commentary has identified the parallels between the game and the television series in terms characters, locations, story beats and imagery, it generally overlooks the ways in which Deadly Premonition is able to translate the subversive uncanniness of Twin Peaks into its novel style of play, which combines survival horror traditions with a free-roaming open world and life-simulation elements. Both the positive and negative reviews of Deadly Premonition have tended to be critical of its gameplay mechanics, viewing them either as fatally flawed (Brudvig 2010) or as poorly implemented systems that could be endured for the sake of an entertaining narrative (Sterling 2010). These assessments overlook the way in which Deadly Premonition's seemingly discordant and inconsistent combination of gameplay features creates an uncanny effect that is similar to that of the contradictory juxtaposition of genres and styles in Twin Peaks.

Upon its release, Deadly Premonition was generally received and evaluated as a survival horror title and this categorization is understandable, given that it shares many of the gameplay features and representational elements commonly associated with this category. In the game's combat focused sections, the player is trapped in the dark, maze-like environments common to survival horror (Kirkland 2005), and the awkward movement and aiming mechanics (reminiscent of Resident Evil (Capcom 1996) work to both highlight the uncanny relationship between the player and their onscreen double (Hoeger and Huber 2007) and to restrict the player's control and field of view in the manner described by Krzywinska, who notes that survival horror games typically position the player as being "unable to act as efficiently as would be expected" (2015b, p. 296). These sections pit the player against the types of uncanny monstrous adversaries that are typical of survival horror games (Perron 2018). As Pruett (2011) notes, player characters in survival horror titles tend to be presented as relatively ordinary in their physical attributes and fighting abilities when compared to the protagonists of more action-oriented video games, and this is true of Francis York Morgan in Deadly Premonition, who has a slow walking and running speed, and limited health in combat. Furthermore, Agent York is frequently presented as overwhelmed by the foes that he faces, being forced to run and hide at various points in game, providing the sense of vulnerability that Hand (2004) identifies as being essential to the success of survival horror.

Despite the presence of these elements, few, if any, reviews suggest that Deadly Premonition is particularly scary to play, which has led to it being received as a flawed or failed survival horror title (Brudvig 2010; Clarkson 2010). Deadly Premonition's general inability to scare the player could be taken as a result of its outdated technology and graphics, which were noted in a number of highly critical reviews, most notably IGN's withering appraisal at the time of its release (Brudvig 2010). In particular, the game 
has a limited number of enemy types when compared to most survival horror titles, and their predictable artificial intelligence resulted in the game's combat sections lacking the sense of surprise and uncertainty that is often considered essential to survival horror (Perron 2012). Furthermore, many players and critics found the game's poor animations unintentionally hilarious, which works to further undermine the scariness of the experience (Sterling 2010). While Deadly Premonition certainly possesses the comparatively awkward third person controls that Hoeger and Huber (2007) identify as contributing to the development of a "gamerly uncanny" in survival horror, its technical limitations mean that this is more likely to result in frustration rather than fear.

However, technical limitations and shortcomings are not the only reason that Deadly Premonition fails to unsettle players in the ways that are expected from a survival horror title. Some conscious design choices work to disrupt and undermine the expected rhythms of survival horror gameplay in interesting ways. In contrast to the minimalism of classic survival horror, Deadly Premonition features an excess and combination of seemingly contradictory gameplay features. Of these, the one that is perhaps most antithetical to the agenda of survival horror, is the open world nature of the game, which allows the player to explore the town of Greenvale in a manner reminiscent of Grand Theft Auto 4 (Rockstar North 2008). While backtracking between previously explored locations is a common feature of survival horror titles, relatively few games within this category provide a genuinely open world for players to freely explore at their leisure. The oppressive, terrifying atmosphere of survival horror games is often linked to the restrictive and claustrophobic environments that they force the player to traverse (Stienmetz 2018; Kirkland 2005), and is generally developed at the expense of player preference or choice, with horror games tending to favor a predetermined or 'on rails' structure (Kirkland 2009a). Girard (2011) goes as far as to argue that it would be impossible to develop the mounting terror that defines survival horror gameplay in a free roaming environment. The relatively few survival horror titles that do provide open worlds usually maintain their tension by surprising the players with aggressive enemies (for example Silent Hill: Downpour [Vatra Games 2012] or The Evil Within 2 [Tango Gameworks 2017]), but this is not the case in Deadly Premonition where the player can explore the town and its surroundings in complete safety between story missions. The player can drive cars, talk to non-player-characters (NPCs), and complete supplementary activities, like darts and fishing mini-games, in a manner reminiscent of adventure/role-playing titles like Shenmue (Sega 1999) and Yakuza (Sega 2005), as well as engaging in life-simulation activities like eating, bathing and sleeping. The populated and welcoming small-town environment that the player explores offers a prolonged relief from the sense of isolation that is often vital to the development of discomfort and terror in survival horror titles (Hand 2004), and the rewards and extra resources accumulated in the open world work to undermine the more conventional survival horror sequences. Survival horror titles tend to place strict limits on the in-game resources that that the player can accumulate to aid them in combat encounters (Perron 2009; Kirkland 2005). This typically forces players to inhabit a "survival space" within the game (Browning 2011), where the decisions they make in regard to exploration and combat are unusually fraught. The open world sections of Deadly Premonition, however, allow them to easily accumulate enough resources to act confidently in most instances, removing this expected tension. Conversely, as the game retains the awkward movement, perspective and navigation controls associated with survival horror titles, the open world exploration in Deadly Premonition does not feel as free and or as fluid as players might expect from games like Grand Theft Auto 4 and its various derivatives.

The deliberate combination of these contradictory modes of gameplay creates an experience that does not feel quite right to the player: a mode of uncanny play that makes the player uncomfortably aware of their movement and mediation of their onscreen avatar, but which does not result in the sense of fear and trepidation that Hoeger and Huber (2007) identify as the purpose of the "gamerly uncanny". Furthermore, the experience that it offers is quite distinct from the "hybridised" forms of survival horror discussed by Perron (2018), where survival horror conventions are combined with other forms of gameplay, such as the actionized survival horror of Resident Evil 4 (Capcom 2005), or the light role-playing 
mechanics incorporated into the character customization in Dead Space (EA Redwood Shore 2008), or the fusion of survival horror with first person shooter found in games like Call of Cthulhu: Dark Corners of the Earth (Headfirst Productions 2005), Pathologic (Ice Pick Lodge 2005) or Alien Isolation (Creative Assembly 2014). In these hybrid games the mechanics and rhythms of the different gaming categories are more-or-less fluidly combined with intention of delivering a terrifying experience. In Deadly Premonition, gameplay features are brought together in a way that contradicts and confuses their usual intentions and pleasures. Its uncanny gameplay does not deliver the terror of the "gamerly uncanny" typically found in survival horror titles, but when coupled with the equally sudden and contradictory shifts in the game's narrative (from horror to surreal comedy to character-focused drama to tragedy) it arguably replicates some elements of the subversive uncanniness of Twin Peaks in a ludic form.

The combination of different and seemingly incompatible gameplay styles (survival horror, open-world adventure, life-simulation and more) in Deadly Premonition mirrors the combinations and juxtapositions of different genres and modes of television storytelling found in Twin Peaks. In both cases, the uncanny experience that results from these combinations works to make the viewer/player intimately aware of the constructed nature of the forms of viewing/gameplay that are being referenced and confounds their expectations, complicating or challenging the audience's immersion. This is further demonstrated through the ways in which both the series and the game integrate seemingly "realistic" elements into their plot/narrative (in the case of the former) and gameplay (in the case of the latter) in ways that make them feel strange and unnatural when placed within the context of television and videogame genres they are drawing upon. Todd McGowan argues that Twin Peaks "often seems unrealistic because of its excess of realism" (McGowan 2016, p. 145)—the show's tendency to focus on mundane exchanges and details that would normally be ignored in television narratives will seem strange to audiences familiar with the rhythms of police procedurals and soap operas. This persists through the typical Lynchian visual fixation on objects and locations in the series-the lingering shots and close-ups of numbered doors, corridors and staircases, curtains, machinery, etc. noted by Molodvan (2015) - where mundane features become strange through the unfamiliar focus and emphasis that is applied to them. A similar uncanniness is generated through the approach to "realistic" detail found in Deadly Premonition. In survival horror games, seemingly realistic objects and settings are traditionally important to deepening the player's immersion in the terrifying experience (Holmes 2010), but some of the excessively realistic elements of Deadly Premonition run counter to this, disrupting the player's immersion due to their lack of practical gameplay utility and their destabilizing contrast with more overtly game-like features. For example, the player has the option to view the interior of the car in first person, with a functioning gas gauge, speedometer, windscreen wipers and turn signals. All of the NPCs in the town follow complex daily schedules, and the player even has the ability to peer through their bedroom windows to watch them sleep at night. These excessively realistic features clash awkwardly with the game's frequent reminders of its own artificiality. These include the cash rewards which appear on screen like points or scores in arcade games; the flashing and rotating icons used to represent health supplies and ammunition; and the names that float above the heads of NPCs in a manner reminiscent of older Japanese role-playing games. In this sense, the excessive realism found in certain aspects of Deadly Premonition's setting and gameplay works to create an uncanny effect in a manner similar to the focus on mundane objects and exchanges in Twin Peaks. In both cases they do not work to heighten the player's immersion in a realistic fictional world but rather deliver an alienating uncanniness due to the sense of strangeness that is created through their seemingly unnecessary presence.

The uncanny excess of both realistic detail and gameplay features found in Deadly Premonition connects it both to Twin Peaks, and the tradition of the Gothic that the series draws upon. In Gothic literature (and its successor the 'Weird' tale) a wealth of detail, description and incident is used prolong rather than resolve the uncertainties of the reader (Krzywinska 2015a), and Gothic narratives are usually set against a background of excess (like castles and manors of rich elites), which provides a symbolic 
frame for the transgressive themes of their narratives (Chess 2015). While survival horror games often indulgence in Gothic sensibilities via some of their representational qualities, particularly their settings and the macabre and transgressive histories that underpin their narratives (Taylor 2009), the expansive and destabilizing excess of the genre is not typically reflected through their minimalist gameplay.

Deadly Premonition's expansion of uncanny play beyond the typical parameters and objectives of survival horror allows it a space to engage with the recurrent focus on doubles and duality that is also found in Twin Peaks. The double is one of the principle areas for the experience of the uncanny (Royle 2003) and in both its narrative and visual imagery, Twin Peaks explores dual or contrasting worlds, characters and identities. Deadly Premonition parallels this fixation in the way it overtly narrativizes the gameplay relationship between the player and their onscreen avatar, Agent York. In doing so it uses the principle mechanism of the "gamerly uncanny" as described to Hoeger and Huber (2007) not to create a sense of terror for the player, but rather to comment upon one of the most powerful expressions of duality in Twin Peaks: the recurrent theme of possession.

\section{Possession in Twin Peaks and Deadly Premonition}

Like Freud, Lacan emphasized the importance of the double or reflection in encounters with or experiences of the uncanny. Where Freud identifies the double as the "uncanny harbinger of death" (Freud [1919] 1955, p. 235), in that the uneasiness it evokes is due to the idea of immortality it implies or creates-a duplicate or repetition that can survive the original-Lacan argues that uncanniness results from the way in which a double or duplicate blurs the boundaries of interiority and exteriority. Lacan defined the territory of the uncanny as extimite, a point where the most intimate interiority of a subject is somehow externalised and separated from them, becoming unfamiliar, threatening or horrifying (Dolar 1991). For Lacan the double or reflection is profoundly uncanny not only because it conveys an intimation of death, but because it transforms what should be the most familiar territory of all—the interior self-into something strange and disconnected.

As Weinstock (2016) notes, possession is the uncanny horror at the heart of Twin Peaks-where the interior self is revealed as an alien duplicate or consciousness. In the series the malevolent spirit Killer BOB is able to inhabit both the bodies and identities of others. Savoy (2016) argues that BOB operates as a literalization of Lacan's model of the uncanny, observing that BOB is often depicted as appearing in mirrors, eerily mimicking the movements and expressions of those he has possessed, an exposure of the interior self that, in a Lacanian sense, transforms it into an alien and menacing countenance. BOB is arguably presented as the ultimate evil in Twin Peaks, the "dark passenger" (Savoy 2016, p. 124) concealed within seemingly benign individuals and the traces of his hidden presence within the show work to transform the familiar tropes and rhythms of the soap opera and the police procedural into something unsettling and sinister.

The preoccupation with possession in Twin Peaks is interesting to consider alongside the ways in which third-person survival horror titles typically foreground and complicate the relationship between the player and their onscreen avatar as a means of producing tension and fear (Kirkland 2009b; Hoeger and Huber 2007). The onscreen avatar serves, at one level, as the player's point of entry and orientation, the game's most familiar and accessible feature. At another level, the disconnection between the player and their avatar, where the player's inputs and commands have delayed, cumbersome or unexpected outcomes, is undeniably uncanny. Hoeger and Huber (2007) suggest that this can be akin to a battle between the player and an unknown intelligence for possession of the onscreen avatar. This uncanniness is occasionally accentuated by games with dialogue and narratives that emphasize the separation of the player and their avatar. In Silent Hill 2 the player is initially unaware of the true history of the protagonist they are controlling and advancing through the game works to alienate the player from their onscreen avatar rather than deepening their identification (Perron 2012). The protagonist of Silent Hill 3 (Konami 2003), Heather, will occasionally address the player directly or refuse to perform an action in ways that make the player uncomfortably aware of the control they are exerting over her in a narrative that revolves around the themes of possession and 
exploitation (Kirkland 2007). In some other titles outside of the survival horror category (for example, Metal Gear Solid [Konami 1998] and The Bureau: XCOM Declassified [2K Marin 2013) moments in the narrative that call overt attention to the player's control and manipulation of their avatar can be likened to Brechtian alienation in that they suddenly expose the system that has been used to produce and prolong the player's immersion and potentially open it to critique (Dunne 2014). In all of these examples the sudden or gradual disruption of the player's identification with their onscreen avatar is presented as an unsettling moment, where the fictional conceit that the player is operating as the interior consciousness of the character is broken.

Conway (2010) argues that these self-aware moments in videogame play do not break the fourth wall in the way that that they do in non-interactive media, where they momentarily or permanently disrupt the suspension of disbelief that allows the audience to emotionally invest themselves in a fictional world or narrative. Rather they have the potential to extend the game's "magic circle" (Huizinga [1938] 1949) to encompass the player themselves, giving traditionally non-diegetic actions diegetic meaning. Deadly Premonition is novel in that it uses this extension to explore the idea of the player as a possessing consciousness in a sustained and consistent way through both narrative and gameplay. As previously noted, the awkward navigation and perspective controls in Deadly Premonition make the player uncannily aware of their distant and mediated relationship with their onscreen avatar. At the same time, however, the narrative of Deadly Premonition works to normalize the duality of player and player character rather than using it to produce moments of discomfort or alienation in the manner of the games mentioned above. Throughout Deadly Premonition, the player character, Agent York, delivers a series of monologues to his apparently imaginary friend named Zach (this is very similar to Agent Cooper's tape-recorded reflections in Twin Peaks, which are directed towards his never-seen secretary Diane). As Deadly Premonition develops, it becomes clear that when York is talking to Zach, he is actually talking directly to the player, and that York seems aware that the player, as Zach, is directing the action. For example, when enemies are approaching in the opening level, York quips "Looks like we've got company, Zach. I'll let you handle the meet and greet", acknowledging that the player is taking control as the game moves from cut-scene to combat. Throughout the game, York regularly congratulates Zach for finding objects and items, and completing in-game tasks and activities. The moments of shock or disruption in the player/avatar relationship described in other games rely heavily on an assumption of direct identification between the player and their avatar in order to have their desired effect. Deadly Premonition, by contrast, emphasizes that the player and the onscreen personality are separate and distinct from the outset, using York's monologues and comments to Zach (which in other narrative games might be explained as the protagonist talking to "themself") to constantly remind the audience of this division. In this sense, the narrative of the game uses the theme of possession to diegetically address the player's constant awareness of their mediated relationship with their onscreen avatar, which has been prompted through Deadly Premonition's uncanny combination of contradictory gameplay.

While the control scheme throughout the game remains uncannily awkward, Zach's control over York's body is presented as natural-when the player chooses to diverge from the critical path to pause or explore, York will typically make an encouraging or accepting comment (e.g., "Seen something Zach? It's okay, we have time."). The final movements of the game's plot reveal that York was an alternative personality created by Zach in response to an acute childhood trauma: the protagonist's true identity has been concealed behind the façade of York all along. While the overt acknowledgement that the player is possessing the protagonist is uncanny, due to its contrast with familiar video game player/avatar relationships, this uncanniness is not used to accentuate the terrifying or alienating atmosphere of typical survival horror titles. The dual identities are presented as working in tandem, with York providing observation and commentary and Zach determining movement and direction. In this sense, Deadly Premonition presents an inversion of the approach to possession found in Twin Peaks. In the series, the "passenger" that resides within and asserts control over a number of the characters is something alien and other, in Deadly Premonition it is presented as a welcome presence-the player 
themselves. By the end of the game, once the true nature of the York/Zach duality has been revealed, York's commentary can be understood as encouragement-prompting Zach/the player to emerge and take direct control and agency. Tellingly, the final moments of the game see the player exploring Greenvale as Zach, who has been stripped of his alternative York personality. The NPCs remaining in the town identify and address the player as Zach, suggesting that the video game character that the players have inhabited or possessed throughout the game has always been a protective fiction and that they have been the true protagonist all along. In this sense, Deadly Premonition reflects or inverts the preoccupation with duality and possession in Twin Peaks to explore the ways in which the player may possess or inhabit a video game protagonist-where the hidden passenger is revealed is revealed not as dangerous or unknowable other but as the true self. The uncanny effect that is created through the York/Zach meta-commentary is distinct from the "gamerly uncanny" that is typically present in survival horror titles. As Hoeger and Huber (2007) note, the "gamerly uncanny" in survival horror is usually created through the disruption or complication of the player's control over their avatar, but this is dependent on a strong sense of identification with the avatar, or at least the desire for it. The exploration of the player/avatar relationship in Deadly Premonition lacks the terrifying or alienating dimensions that might be expected from survival horror titles, but it is nonetheless distinctly and provocatively uncanny, as it works to dispute this need for the familiar illusion of a singular identification, rather engaging with (and exposing) the player/avatar relationship as a possessive duality.

\section{Conclusions: The Uncanniness of Deadly Premonition}

While it can be understood simply as a flawed or failed video game title, an appreciation of the unusual uncanniness of Deadly Premonition helps to explain its niche appeal and divided critical reception. Hoeger and Huber (2007) define the "gamerly uncanny" as an uncanniness that develops not just out of a game's representational elements, but also from the ways in which it renders familiar videogame actions and relationships as strange. They argue that the "gamerly uncanny" develops principally out of the ways in which games, and in particular survival horror titles, disrupt or complicate the player's relationship with their onscreen avatar. Deadly Premonition serves to demonstrate how this idea of the "gamerly uncanny" can be expanded upon and explored more deeply in order to deliver a novel gameplay experience. It's distinctly uncanny character results from a number of interconnected elements. In contrast to typical survival horror design, which is usually defined by the limitations it places on the player and a minimalist aesthetic, Deadly Premonition offers expansion and excess, combining a range of gameplay styles and experiences. This has the effect of rendering familiar gameplay features strange and uncanny to the player due to their apparent incompatibility and contradictory outcomes. Deadly Premonition disrupts not just the familiar player/avatar relationship, but the familiarity of the survival horror category of gameplay itself in order to deliver a distinctly uncanny effect. In this sense, it is very similar to the genre-bending elements of its source material Twin Peaks, which used the juxtaposition of different styles of familiar television narratives to subvert the expectations of its audience. It should be noted that it is difficult to establish the extent to which these outcomes align with the original intentions of the game's developers. The director, Hidetaka "SWERY" Suehiro, is reportedly unwilling to directly acknowledge the influence of Twin Peaks on Deadly Premonition despite the many obvious parallels between the series and the game (Kumar 2011). Furthermore, it is by no means certain that the uncanny elements of its gameplay which result from conscious design decisions, such as the deliberate combination of seemingly contradictory categories and styles of play, were intended to have a subversive effect. However, Deadly Premonition has been largely received and understood as a homage, parody or quasi-adaptation of Twin Peaks, and intentionally or not, its uniquely uncanny aesthetic and atmosphere parallels that of the series and has a similarly effect on its audience. A significant number of games demonstrate the clear influence of Twin Peaks in their narrative and visuals, but the destabilizing uncanniness of Deadly Premonition connects it to the themes of the series through both its representational and gameplay 
elements. Its foregrounding of the themes of duality and possession leads to a provocative commentary on the player/avatar relationship, which is expressed through its both its narrative and gameplay. Deadly Premonition ultimately works to demonstrate the ways in which uncanny play can be used not just to create a sense of fear or alienation, but also a sophisticated self-awareness in relation to familiar and accepted relationships between videogame narrative and gameplay features.

Funding: This research received no external funding.

Conflicts of Interest: The author declares no conflict of interest.

\section{References}

2K Marin. 2013. The Bureau: XCOM Declassified. PC, PlayStation 3, Xbox 360. Novato: 2K Games. Access Games. 2010. Deadly Premonition. PlayStation 3, Xbox 360. Tokyo: Marvellous Entertainment. Atlus. 2008. Persona 4. PlayStation 2, PlayStation Vita. Tokyo: Atlus.

Botting, Fred. 2008. Limits of Horror: Technology, Bodies, Gothic. Manchester and New York: Manchester University Press. Browning, John Edgar. 2011. Survival Horrors, Survival Spaces: Tracing the Modern Zombie (cine) Myth. Horror Stories 2: 41-59. Available online: https://www.academia.edu/6697551/_Survival_Horrors_Survival_ Spaces_Tracing_the_Modern_Zombie_Cine_Myth_HORROR_STUDIES_2011_uncorrected_proof_ (accessed on 29 June 2018).

Brudvig, Erik. 2010. Deadly Premonition Review. IGN, February 22. Available online: http:/ / au.ign.com/articles / 2010/02/23/deadly-premonition-review (accessed on 22 June 2018).

Capcom. 1996. Resident Evil. Playstation. Osaka: Capcom.

Capcom. 2005. Resident Evil 4. Gamecube. PC. PlayStation 2. Osaka: Capcom.

Carmicheal, Stephanie. 2013. How Twin Peaks Finds New Life in the World of Deadly Premonition. Kill Screen, April 30. Available online: https:/ / killscreen.com/articles/how-twin-peaks-finds-new-life-world-deadlypremonition/ (accessed on 29 June 2018).

Chess, Shira. 2015. Uncanny Gaming: The Ravenhearst Videogames and Gothic Appropriation. Feminist Media Studies 15: 382-96. [CrossRef]

Clarkson, Sparky. 2010. Deadly Premonition Review. Game Critics, March 14. Available online: https://gamecritics. com/sparky-clarkson/deadly-premonition-review / (accessed on 29 June 2018).

Clifftop Games. 2016. Kathy Rain. PC. Stockholm: Raw Fury.

Conway, Steven. 2010. A Circular Wall? Reformulating the Fourth Wall for Videogames. Journal of Gaming and Virtual Worlds 2: 145-55. [CrossRef]

Creative Assembly. 2014. Alien Isolation. PC, PlayStation 3, PlayStation 4, Xbox 360, Xbox One. Tokyo: Sega.

Dolar, Mladen. 1991. "I Shall Be with You on Your Wedding-Night": Lacan and the Uncanny. October 58: 5-23. Available online: https:/ / www.jstor.org/stable/778795 (accessed on 29 June 2018).

Dontnod Entertainment. 2015. Life is Strange. PC, PlayStation 3, PlayStation 4, Xbox 360, Xbox One. Tokyo: Square Enix. Dunne, Daniel. 2014. Brechtian Alienation in Videogames. Press Start 1: 79-99. Available online: https://pressstart.gla.ac.uk/index.php/press-start/article/view/8/7 (accessed on 29 June 2018).

EA Redwood Shore. 2008. Dead Space. PC, PlayStation 3, Xbox 360. Redwood City: EA.

Freud, Sigmund. 1955. The Uncanny. In The Standard Edition of the Complete Psychological Works of Sigmund Freud, Volume XVII (1917-1919): An Infantile Neurosis and Other Works. Translated by James Strachey. London: The Hogarth Press. First published 1919. pp. 213-56.

Frost, Mark, and David Lynch. 1990-1991. Twin Peaks. Performed by Kyle MacLachlan, Michael Ontkean, Mädchen Amick, Dana Ashbrook, Richard Beymer, Lara Flynn Boyle, Sherilyn Fenn, Warren Frost, Peggy Lipton, James Marshall, and et al. Los Angeles: Lynch/Frost Productions and Spelling Television Inc.

Girard, Pavel. 2011. "The Fear System"—Triggering Tension in Survival Horror Videogames. Norderstedt: GRIN Verlag.

Green, Holly. 2017. 9 Games to Play if you love Twin Peaks. Paste Magazine, May 21. Available online: https: / / www.pastemagazine.com/articles/2017/05/9-games-to-play-if-you-loved-twin-peaks.html (accessed on 29 June 2018).

Hand, Richard J. 2004. Proliferating Horrors: Survival Horror and the Resident Evil Franchise. In Horror Film: Creating and Marketing Fear. Edited by Steffan Hantke. Jackson: University Press of Mississippi, pp. 117-34. Headfirst Productions. 2005. Call of Cthulhu: Dark Corners of the Earth. PC, Xbox. Rockville: Bethesda Softworks. 
Hoeger, Lauren, and William Huber. 2007. Ghastly multiplication: Fatal Frame II and the Videogame Uncanny. Paper presented at the 2007 DiGRA International Conference: Situated Play, Tokyo, Japan, September 24-28; Edited by Akira Baba. pp. 152-56. Available online: http:/ /www.digra.org/wp-content/uploads/digitallibrary/07313.12302.pdf (accessed on 29 June 2018).

Holmes, Eben. 2010. Strange Reality: Glitches and Uncanny Play. Eludamos. Journal for Computer Game Culture 4: 255-76. Available online: http://eludamos.org/index.php/eludamos/article/view/vol4no2-9/188 (accessed on 29 June 2018).

Huizinga, Johan. 1949. Homo Ludens: A Study of the Play-Element in Culture. London: Routledge. First published 1938. Ice Pick Lodge. 2005. Pathologic. PC. Moscow: Ice Pick Lodge.

Jentsch, Ernst. 1995. On the Psychology of the Uncanny. Translated by Roy Sellars. Angelaki 2: 7-16. [CrossRef]

Jowett, Lorna. 2016. Nightmare in red: Twin Peaks parody, homage and mashup. In Return to Twin Peaks: New Approaches to Materiality, Theory, and Genre on Television. Edited by Jeffery Andrew Weinstock and Catherine Spooner. New York: Palgrave Macmillan, pp. 211-27.

Kirkland, Ewan. 2005. Restless Dreams in Silent Hill: Approaches to Videogame analysis. The Journal of Media Practice 6: 183-95. [CrossRef]

Kirkland, Ewan. 2007. The Self-Reflexive Funhouse of Silent Hill. Convergence 3: 403-15. [CrossRef]

Kirkland, Ewan. 2009a. Storytelling and Survival Horror. In Horror Video Games. Edited by Bernard Perron. Jefferson: McFarland \& Company, Inc., pp. 26-45.

Kirkland, Ewan. 2009b. Horror Videogames and the Uncanny. Paper presented at the 2009 DiGRA International Conference: Breaking New Ground: Innovation in Games, Play, Practice and Theory (DiGRA '09), London, UK, September 1-4. Available online: http:/ / www.digra.org/wp-content/uploads/digital-library /09287. 25453.pdf (accessed on 29 June 2018).

Konami. 1998. Metal Gear Solid. PC, PlayStation. Tokyo: Konami.

Konami. 2001. Silent Hill 2. PlayStation 2, Xbox. Tokyo: Konami.

Konami. 2003. Silent Hill 3. PlayStation 2. Tokyo: Konami.

Konami. 2008. Silent Hill Homecoming. PC, PlayStation 3, Xbox 360. Tokyo: Konami.

Kristeva, Julia. 1982. Powers of Horror: An Essay on Abjection. Translated by Leon S. Roudiez. New York: Columbia University Press.

Krzywinska, Tanya. 2002. Hands-On Horror. In Screenplay: Cinema/Videogames/Interfaces. Edited by Geoff King and Tanya Krzywinska. London: Wallflower Press, pp. 206-23.

Krzywinska, Tanya. 2015a. Conspiracy Hermeneutics: The Secret World as Weird Tale. Well Played 3: 119-38.

Krzywinska, Tanya. 2015b. Gaming Horror's Horror: Representation, Regulation, and Affect in Survival Horror Video Games. Journal of Visual Culture 14: 293-97. Available online: http:/ /vcu.sagepub.com/content/14/3/ 293.abstract?rss=1 (accessed on 29 June 2018).

Kumar, Matthew. 2011. The 'Swery Game': Hidetaka Suehiro on Deadly Premonition. Gamasutra, June 3. Available online: https:/ / www.gamasutra.com/view/feature/134764/the_swery_game_hidetaka_suehiro_ .php (accessed on 29 June 2018).

McGowan, Todd. 2016. Lodged in a Fantasy Space: Twin Peaks and Hidden Obscenities. In Return to Twin Peaks: New Approaches to Materiality, Theory, and Genre on Television. Edited by Jeffery Andrew Weinstock and Catherine Spooner. New York: Palgrave Macmillan, pp. 143-57.

Molodvan, Raluca. 2015. "That Show You Like Might Be Coming Back in Style": How Twin Peaks Changed the Face of Contemporary Television. American, British and Canadian Studies 24: 44-68. [CrossRef]

Mori, Masahiro. 2012. The Uncanny Valley. IEEE Spectrum, June 12. Translated by Karl F. MacDorman and Norri Kageki. First published 1970. Available online: https://spectrum.ieee.org/automaton/robotics/ humanoids / the-uncanny-valley (accessed on 29 June 2018).

Perron, Bernard. 2009. Introduction: Gaming after Dark. In Horror Video Games. Edited by Bernard Perron. Jefferson: McFarland \& Company, Inc., pp. 13-14.

Perron, Bernard. 2012. Silent Hill: The Terror Engine. Ann Arbor: University of Michigan Press.

Perron, Bernard. 2018. The World of Scary Videogames: A Study in Videoludic Horror. New York: Bloomsbury Academic.

Pruett, Chris. 2011. “Designing Characters to Be Scared For", Chris's Survival Horror Quest [blog]. June 12. Available online: http:/ / horror.dreamdawn.com/?p=60990 (accessed on 29 June 2018).

Remedy Entertainment. 2010. Alan Wake. Xbox 360. Redmond: Microsoft Game Studios.

Rockstar North. 2008. Grand Theft Auto 4. PC, PlayStation 3, Xbox 360. New York: Rockstar Games. 
Rockstar North. 2013. Grand Theft Auto 5. PC, PlayStation 3, Xbox 360. New York: Rockstar Games.

Royle, Nicholas. 2003. The Uncanny. New York: Routledge.

Savoy, Eric. 2016. Jacques Lacan, Walk with Me: On the Letter. In Return to Twin Peaks: New Approaches to Materiality, Theory, and Genre on Television. Edited by Jeffery Andrew Weinstock and Catherine Spooner. New York: Palgrave Macmillan, pp. 123-41.

Schneider, Steven Jay. 2004. Manifestations of the Literary Double in Modern Horror Cinema. In Horror Film and Psychoanalysis: Freud's Worst Nightmare. Edited by Steven Jay Schneider, William Rothman and Dudley Andrew. Cambridge: Cambridge University Press, pp. 106-21.

Sega. 1999. Shenmue. Nintendo Gamecube. Tokyo: Sega.

Sega. 2005. Yakuza. PlayStation 2. Tokyo: Sega.

Sterling, Jim. 2010. Review: Deadly Premonition. Destructoid, February 27. Available online: https://www. destructoid.com/review-deadly-premonition-165168.phtml (accessed on 29 June 2018).

Stienmetz, Kevin F. 2018. Carceral horror: Punishment and control in Silent Hill. Crime, Media Culture: An International Journal 14: 265-87. [CrossRef]

Tango Gameworks. 2017. The Evil within 2. PC, PlayStation 4, Xbox One. Rockville: Bethseda Softworks.

Taylor, Laurie. 2009. Gothic Bloodlines in Survival Horror Gaming. In Horror Video Games. Edited by Bernard Perron. Jefferson: McFarland \& Company, Inc., pp. 46-61.

Terrible Toybox. 2017. Thimbleweed Park. Terrible Toybox.

Thomsen, Michael. 2010. Revival Horror: New Ideas in Fear-Making. Gamasutra, June 1. Available online: http:/ / www.gamasutra.com/view / feature/134160/revival_horror_new_ideas_in_.php (accessed on 29 June 2018).

Tinwell, Angela, and Mark Grimshaw. 2009. Survival Horror Games-An Uncanny Modality. Paper presented at the Thinking after Dark Conference, Montreal, QC, Canada, April 23-25. Available online: http://www. academia.edu/1358775/Tinwell_A._and_Grimshaw_M._2009_Survival_horror_games_-_an_uncanny_ modality_paper_presented_at_the_Thinking_After_Dark_Conference_Montreal_Canada_23-25_April (accessed on 29 June 2018).

Ubisoft. 2003. Beyond Good and Evil. Gamecube, PC, PlayStation 2, Xbox. Montreuil: Ubisoft.

VanOrd, Kevin. 2010. Deadly Premonition Review. Gamespot, April 19. Available online: https:/ /www.gamespot. com/reviews/deadly-premonition-review/1900-6258973/ (accessed on 29 June 2018).

Variable State. 2016. Virginia. Mac, PC, PlayStation 4, Xbox One. Milan: 505 Games.

Vatra Games. 2012. Silent Hill: Downpour. PlayStation 3, Xbox 360. Tokyo: Konami.

Wales, Matt. 2010. Deadly Premonition UK Review. IGN, November 8. Available online: http://au.ign.com/ articles/2010/11/08/deadly-premonition-uk-review (accessed on 29 June 2018).

Weinstock, Andrew. 2016. Wondrous and Strange: The Matter of Twin Peaks. In Return to Twin Peaks: New Approaches to Materiality, Theory, and Genre on Television. Edited by Jeffery Andrew Weinstock and Catherine Spooner. New York: Palgrave Macmillan, pp. 29-46.

(C) 2018 by the author. Licensee MDPI, Basel, Switzerland. This article is an open access article distributed under the terms and conditions of the Creative Commons Attribution (CC BY) license (http:/ / creativecommons.org/licenses/by/4.0/). 